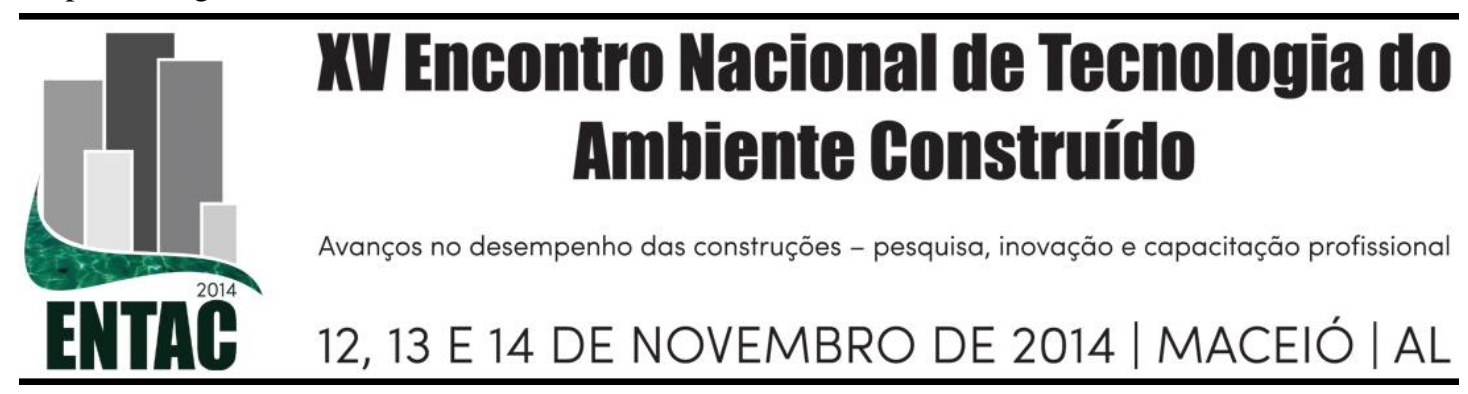

\title{
ANÁLISE DO CONSUMO DE ÁGUA EM PRÉDIO COM CERTIFICAÇÃO AMBIENTAL
}

\author{
ANTONIOLLI, Cibele B (1); KERN, Andrea P (2); WANDER, Paulo R (3); \\ HERRMANN, Julia C (4); OLIVEIRA, Carla P (5) \\ (1) UNISINOS, (51) 3591.1122, e-mail: cibeleantoniolli@gmail.com (2) UNISINOS, e-mail: \\ apkern@unisinos.br (3) UNISINOS, e-mail: prwander@unisinos.br (4) UNISINOS, e-mail: \\ juliaherrmann@uol.com.br (5) UNISINOS, e-mail: jagadambaoliv@gmail.com
}

\begin{abstract}
RESUMO
Os selos de certificação ambiental surgem como uma ferramenta de projeto, execução e desempenho (pós-ocupação), voltada a questões de sustentabilidade, envolvendo a diminuição de diferentes impactos ambientais, sociais e econômicos. O presente trabalho é parte de uma Dissertação de Mestrado que se encontra em desenvolvimento, e tem como objetivo analisar o conjunto de decisões tomadas na fase de projeto de um prédio comercial, certificado no nível ouro do programa LEED, visando à redução no consumo de água. A estratégia de pesquisa consiste num estudo de caso onde está sendo analisado o consumo de água no prédio durante os quatro anos de ocupação. Para tanto foram consideradas informações do sistema de automação quanto ao consumo de água neste período e comparadas a parâmetros encontrados na bibliografia do LEED e no consumo de água previsto na etapa de projeto, informação que concedeu a pontuação no programa de certificação, que especifica uma redução de $30 \%$ em relação ao consumo de água em comparação com prédios tradicionais (sem diretrizes de sustentabilidade). Os resultados parciais indicam que o conjunto das iniciativas voltadas a esta questão nem sempre resultam na economia esperada pelo projeto. Como contribuição, a discussão dos resultados é realizada a partir dos dados de consumo das diferentes iniciativas propostas pelo projeto, que incluem a construção de uma estação de tratamento de esgoto (ETE), otimização do projeto de paisagismo, dispositivos redutores de vazão, analisando toda a operação do prédio (facilidade e dificuldades).
\end{abstract}

Palavras-chave: certificação ambiental, consumo de água, pós-ocupação de edificação.

\begin{abstract}
The environmental certification labels emerge as a tool for project design, construction and performance phase (post-occupancy), oriented to sustainability issues, involving the reduction of different environmental, social and economic impacts. The present paper is part of a MSc's dissertation that is currently under development, and its purpose is to analyze the design decisions taken on a commercial building, with the LEED environmental certification at level "Gold", aiming the water consumption reduction. The research method consists in a study case in which the water consumption of the building is analyzed during four years of occupancy. Therefore, automation system information will be analyzed regarding the water consumption in this time frame and compared to LEED literature's guidelines and also to the water consumption expected on the building's design phase, information that granted a specific score on the certification program that establishes a water reduction of at least 30\% compared to traditional buildings (with no environment guidelines). The partial results suggest that the design initiatives taken not always result on the expected design economy reduction. As contribution, the results' debate considers the different consumption data of the solutions proposed by the project design, including a Sewage Treatment Plant (STP), landscaping design optimization, water flow reducer devices, and all the building operation analysis (facilities and difficulties).
\end{abstract}

Keywords: environmental certification, water consumption, building post-occupancy. 


\section{INTRODUÇÃO}

A construção civil caracteriza-se como uma das maiores consumidoras de recursos naturais em seu processo produtivo, tanto no Brasil como no exterior (JOHN, 2000). Os impactos ambientais causados por um edifício ocorrem em todas as etapas que compreende seu ciclo de vida, iniciando-se pela extração de matérias-primas, produção e transporte dos materiais e componentes, geração de resíduos durante a fase de construção e ao final da vida útil. Conforme John Oliveira e Agopyan (2006), a indústria consome cerca de $75 \%$ dos recursos naturais do mundo, em sua maioria não renováveis. Além desses, citam-se o consumo de energia e água e a geração de efluentes durante a fase de pós-ocupação. Em relação ao consumo de água, foco deste trabalho, Macozonma (2002) diz que o setor da construção civil é responsável pelo consumo de 2-16\% de água potável.

Desde a década de 80, desenvolvimento sustentável, ou sustentabilidade tornamse cada vez mais discutidos por acadêmicos envolvidos com a construção civil (PACHECO TORGAL; JALALI, 2010). A Figura 1 apresenta a quantidade de trabalhos acadêmicos que discorrem sobre o assunto ao longo do tempo.

\section{Figura 1 - Artigos que contém o termo "desenvolvimento sustentável” na área da}

\section{construção civil}

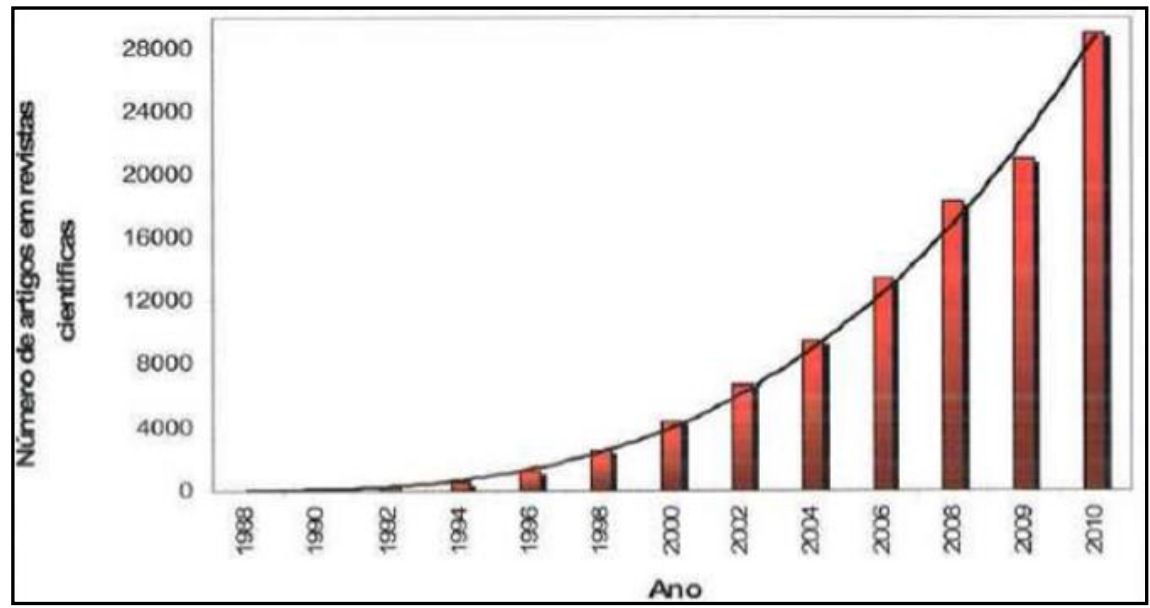

Fonte: Pacheco, Torgal e Jalali (2010)

A partir do crescimento do volume de obras ao longo das últimas duas décadas, constata-se que o mundo científico se volta com grande interesse a esse relevante tema. Em paralelo, surgem novas tendências no mercado para promover uma mudança de paradigmas de consumo do setor da construção civil, por meio do incentivo ao uso racional de recursos naturais e da preferência por aqueles produzidos regionalmente, bem como a de reciclagem dos materiais, para que produtos e serviços estejam comprometidos com a preservação do meio ambiente em diferentes formas. Os países que acreditavam dominar os conceitos dos chamados "projetos ecologicamente corretos", ou prédios verdes, não possuíam meios para verificar quão sustentáveis eram de fato os seus edifícios. Assim surgiu a necessidade de criação de ferramentas, programas ou sistemas de avaliação e certificação, com o objetivo de orientar empreendedores, projetistas e construtores quanto aos aspectos a serem considerados na produção de edificações mais sustentáveis (SILVA; SILVA; AGOPYAN, 2003). Ou seja, de acordo com Gonçalves e Duarte (2006), uma certificação ambiental é concedida a partir de um sistema de avaliação onde se analisa o grau de sustentabilidade associado à uma edificação, em razão de determinados critérios de desempenho aplicados nele. 
Existem no mercado diferentes certificações ambientais, cujo escopo e quesitos dependem de cada país, bem como suas reais necessidades (BENINI et al., 2003). Os principais sistemas de avaliação internacional atualmente são: AQUA (Brasil), Beam (China), BREEAM (Reino Unido), CASBEE (Japão), Démarche HQE® (França), Energy Star ${ }^{\circledR}$ (Estados Unidos), GBTool ${ }^{\circledR}$, Green Mark Scheme ${ }^{\circledR}$ (Singapura), Green Star SA ${ }^{\circledR}$ (Australia), LEED ${ }^{\circledR}$ (Estados Unidos), MSDG ${ }^{\circledR}$ (Estados Unidos) e NABERS ${ }^{\circledR}$ (Australia). No Brasil, o interesse na avaliação ambiental de edificações é relativamente recente, e atualmente os principais selos nacionais são: AQUA ${ }^{\circledR}$, Fundação Vanzolini ${ }^{\circledR}$, Programa Procel Edifica ${ }^{\circledR}$, Selo da Caixa azul ${ }^{\circledR}$ e Sustentax ${ }^{\circledR}$.

A norte-americana LEED (Leadership in Energy \& Environmental Design) consiste no primeiro sistema de certificação internacional a ser adotado por empresas brasileiras. Dentre as principais críticas a este sistema, a principal refere-se à aplicação de normas americanas para parâmetros de desempenho, que por vezes não correspondem à realidade brasileira, já que uma avaliação tecnicamente consistente deve refletir as prioridades do país (STUERMER; BEDENDO; FELIPETTE, 2010). Outro fator a ser considerado, é que não existe recertificação nesta categoria do LEED de novas construções, ou seja, não há a necessidade de renovação do certificado. Ele é válido apenas para as decisões de projeto e execução, não levando em conta o desempenho de pós-ocupação.

Para obter esta certificação o empreendimento deve atender aos pré-requisitos mínimos e obter uma pontuação mínima junto aos requisitos, sendo então enquadrado em um sistema de classificação no qual se atribui o nível de conformidade, podendo ser simplesmente certificado, prata, ouro ou platina. O sistema aplica-se também a oito modalidades de certificações LEED, que podem ser atribuídas a novos projetos ou a edificações existentes. No país há 390 empreendimentos certificados pelo sistema LEED, 13 destes localizados no Rio Grande do Sul (“Green Building Council Brasil”, 2014).

Existe uma série de dificuldades ao implementar selos internacionais, uma vez que se tratando de países com latitudes, condições sociais e econômicas e ambientais tão diferentes, uma melhor atenção deve ser dada ao se importar um selo ambiental internacional. Além das práticas construtivas e de projeto serem diferentes de país para país, a receptividade do mercado à introdução de métodos é um fator relevante a ser levado em consideração (SILVA; SILVA; AGOPYAN, 2003). Para garantir o sucesso de uma implementação de selo ambiental internacional, os autores reforçam para a educação dos usuários e dos projetistas, para a evolução da qualidade na especificação de projeto, e para a apresentação de um plano de manutenção e um manual do usuário.

O presente trabalho é parte de uma Dissertação de Mestrado que se encontra em desenvolvimento. Tem como objetivo analisar o conjunto de medidas tomadas na fase de um projeto de um prédio comercial, certificado no nível ouro do programa LEED, visando à redução no consumo de água.

\section{MÉTODO DE PESQUISA}

A estratégia de pesquisa consiste num estudo de caso que utiliza como objeto de estudo um prédio ambientalmente certificado, sede de uma empresa da área de TI (tecnologia de informação) localizado no Rio Grande do Sul. A área total do edifício é de aproximadamente 11.250 metros quadrados. Sua construção foi iniciada em 2007, e está ocupado desde 2009.

A pesquisa foi realizada em duas etapas, a seguir descritas: 


\subsection{Etapa 1: identificação das soluções de projeto para atendimento de requisitos}

A partir dos pré-requisitos e requisitos do programa de certificação da categoria "Eficiência da Água" (Quadro 1) foram identificadas as soluções indicadas no projeto, que concederam a pontuação para o selo de certificação ambiental. Essas informações foram pesquisadas nos projetos e na documentação enviada ao órgão certificador.

\section{Quadro 1 - Requisitos pontuados na categoria "Eficiência da Água"}

\begin{tabular}{|c|l|}
\hline \multicolumn{2}{|c|}{ Pré-requisitos e requisitos para avaliação LEED } \\
\hline 1 & Uso eficiente de água no paisagismo, reduzir em $50 \%$ \\
\hline 2 & Uso eficiente de água no paisagismo, não utilização de água potável ou sem irrigação \\
\hline 3 & Tecnologias inovadoras para águas residuais \\
\hline 4 & Redução do uso de água: $20 \%$ de redução \\
\hline 5 & Redução do uso de água: $30 \%$ de redução \\
\hline
\end{tabular}

Fonte: Autora (2014)

\subsection{Etapa 2: dados de consumo de água}

Para a análise do consumo de água do prédio durante seus quatro anos de ocupação, foram buscadas informações provenientes da medição do consumo de água nos hidrômetros localizados junto aos reservatórios de água, a partir do controle de medições realizado pela equipe terceirizada de manutenção predial e também informações do sistema de automação quanto ao consumo de água neste período.

Para avaliar o consumo, estes dados foram comparados com o consumo de água previsto na etapa de projeto e com o consumo mínimo estabelecido pelo programa LEED.

\section{RESULTADOS E DISCUSSÕES}

\subsection{Soluções de projetos adotadas para o atendimento aos requisitos da categoria "Eficiência da Água"}

Para o atendimento dos requisitos referentes à irrigação do paisagismo (Requisitos 1 e 2, Quadro 1), na etapa de projeto, segundo orientações do programa LEED, os projetistas devem optar entre quatro alternativas: (1) o paisagismo e sistema de irrigação são destinados a reduzir o consumo de água em irrigação, baseado em um cálculo de referência; (2) a água de irrigação utilizada no prédio é de fonte não potável; (3) o paisagismo e sistema de irrigação são designados a reduzir o consumo de água em irrigação, baseado em um cálculo de referência + a água de irrigação utilizada no prédio é de fonte não potável; ou (4) o paisagismo não requer sistema de irrigação permanente. Sistemas de irrigação temporários para a consolidação do paisagismo serão removidos em um ano de instalação.

No projeto optou-se pela alternativa 3 , que requer $50 \%$ de redução no consumo de água potável para garantir 1 ponto na certificação ambiental e onde uma redução no consumo de água potável de $100 \%$ + redução de $50 \%$ no consumo total de água garantem 2 pontos. 
A solução de projeto previu a utilização de água não potável para irrigação do paisagismo. Para isso, a irrigação seria realizada pela água de reuso, tratada na estação de tratamento de esgoto (ETE) construída para uso exclusivo do prédio.

Neste requisito o projeto do prédio propõe $100 \%$ de redução de água potável e $75,4 \%$ de redução no consumo total de água (ganhando 2 pontos no requisito).

Para atendimento dos demais requisitos, referentes a tecnologias de águas residuais e redução do consumo (Requisitos 3, 4 e 5, Quadro 1), os projetistas devem optar entre duas alternativas: (1) cálculo de economia de água ou (2) tratamento de águas residuais no local.

No requisito "Tecnologias inovadoras para águas residuais", optou-se pela alternativa 1, onde a ETE (estação de tratamento de esgoto) foi projetada para suprir e gerar exatamente a quantidade total necessária para suprir o uso, tornando em $100 \%$, a economia de água potável no edifício. De acordo com os cálculos de referência do LEED, esta solução reduz $460 \%$ de transporte de esgoto para a cidade, quando o LEED requer que este número seja apenas de $50 \%$.

Já nos requisitos de "Redução no uso de água", o projeto considerou a ocupação de 400 pessoas no prédio, entre elas 374 pessoas fixas ( 187 homens e 187 mulheres), e população flutuante de 4 visitantes e 22 terceiros. Também foi declarado que todos os banheiros masculinos possuem mictórios, e foram contabilizados 260 dias de operação em um ano. Nestes requisitos, o projeto prevê a redução de $65,8 \%$ no consumo total de água. De acordo com o LEED, ao se atingir 20\% neste valor, ganha-se 1 ponto, e $30 \%$ ganha 2 pontos. O Quadro 2 mostra as soluções de projeto adotadas para cumprimento dos requisitos da categoria "Eficiência da Água".

\section{Quadro 2 - Requisitos pontuados e suas soluções de projeto}

\begin{tabular}{|c|c|c|}
\hline \multicolumn{2}{|r|}{ Pré-requisitos e requisitos para avaliação LEED } & \multirow{3}{*}{\begin{tabular}{|l|} 
Soluções de projeto adotadas \\
$\begin{array}{l}\text { Uso de água não potável para irrigação, } \\
\text { proveniente da ETE }\end{array}$
\end{tabular}} \\
\hline 1 & $\begin{array}{l}\text { Uso eficiente de água no paisagismo, reduzir em } \\
50 \%\end{array}$ & \\
\hline 2 & $\begin{array}{l}\text { Uso eficiente de água no paisagismo, não } \\
\text { utilização de água potável ou sem irrigação }\end{array}$ & \\
\hline 3 & Tecnologias inovadoras para águas residuais & ETE \\
\hline 14 & Redução do uso de água: $20 \%$ de redução & \multirow{2}{*}{$\begin{array}{l}\text { Uso de água não potável (ETE) para } \\
\text { descargas e mictórios. Uso de aeradores } \\
\text { em torneiras e chuveiros abastecidos de } \\
\text { água potável. }\end{array}$} \\
\hline 3 & Redução do uso de água: $30 \%$ de redução & \\
\hline
\end{tabular}

Fonte: Autora (2014)

Porém, observou-se que, além de todas as medidas de projeto citadas anteriormente, dois elementos se destacam como grandes consumidores de água, e são usados no cumprimento de outros requisitos do programa LEED. O primeiro refere-se ao ar condicionado e o segundo consiste no espelho d'água localizado no térreo, no centro do prédio, construído com o objetivo de diminuir ilha de calor entre os blocos do edifício e por agregar valor estético ao paisagismo. 


\subsection{Consumos de água: parâmetros do programa de certificação, parâmetros previstos no projeto e dados do consumo real}

A seguir são apresentados os parâmetros de consumo de água estabelecidos pelo LEED, os parâmetros de consumo de água previstos no projeto e dados de medição do consumo de água no prédio.

\section{- Requisitos 1 e 2: uso eficiente de água de paisagismo}

O LEED determina este cálculo de referência através da medição de áreas de vegetação associados a dois tipos de irrigação: aspersor e gotejamento (cada um com um índice de eficiência de irrigação) e alguns fatores como: coeficiente de tipo de paisagismo, fator das espécies, fator de densidade e fator de microclima fazem parte deste cálculo. Com base nisso, foram determinados 137.711 galões (cerca de 521.925 litros) de consumo de água para irrigação por mês.

O projeto do prédio prevê apenas 33.923 galões (cerca de 128.569 litros) por mês para suprir o consumo de irrigação conforme o projeto, que é proveniente da ETE (estação de tratamento de esgoto, que é uma fonte não potável). O projeto justifica este baixo consumo de água através do uso de um sistema de irrigação que mistura aspersores e irrigação por gotejamento e também o uso de arbustos nativos adaptados ("vedélias"), que não necessitam de um sistema de irrigação permanente.

Dados que mostram o consumo durante a fase de ocupação do prédio apontam que a quantidade consumida é aproximadamente 395 litros por mês, considerando que o sistema é acionado $1 \mathrm{vez}$ ao dia durante um período de 10 a 15 minutos, em dias sem chuva.

\section{- Requisito 3: tecnologias inovadoras para águas residuais}

O LEED determina o cálculo de referência através da declaração da população que ocupará o prédio, entre elas fixa e flutuante, aliada ao total de horas de funcionamento do prédio. A partir disso são determinadas quantidades de descargas acionadas por pessoa, resultando no fluxo de descarga total do edifício. Com base nesse parâmetro, foi determinado que a ETE deve tratar cerca de 5.206.301 litros (1.373.694 galões) de água anualmente. Destes cerca de 1.253.088 (330.630 galões) seriam utilizados para reabastecimento dos reservatórios de água de reuso do prédio e cerca de 3.953.213 litros (1.043.064 galões) seriam infiltrados no solo.

O projeto do prédio previu a necessidade de 1.253.088 litros de água tratada da ETE, considerando 1.131.831 litros para reabastecimento do prédio, e 128.569 litros para a irrigação do paisagismo, valor já declarado no requisito anterior, não sendo declaradas quantidades a serem utilizadas no reabastecimento e infiltrados no solo.

Dados do consumo mensal entre fevereiro de 2013 a janeiro de 2014 mostram que a ETE trata 3.414.530 litros de água anualmente. Destes, 2.928.214 litros são utilizados para reabastecimento dos reservatórios de água de reuso do prédio e 486.617 litros são infiltrados no solo.

\section{- Requisitos 4 e 5: redução do uso de água}

O LEED determina o cálculo de referência através de parâmetros de uso de torneiras, chuveiros, mictórios e bacias sanitárias, a partir da declaração do número de ocupantes do prédio e relacionado a quantidade de horas que eles ficarão no edifício, igual ao requisito anterior. Também são declaradas as especificações técnicas dos metais de banheiro, com seu respectivo valor de vazão de água. Com base nisso, foi determinado 
que são necessários cerca de 1.641.596 litros (433.139 galões) por ano na utilização de água na descarga de sanitários e mictório, que seja proveniente da ETE. Já para torneiras de pia, copas e chuveiros, o cálculo de referência do LEED prevê fluxo de vazão de água potável em cerca de 1.488.939 litros/ano (392.860 galões).

No projeto do prédio foi previsto que cerca de 1.131.831 litros/ano de água da ETE são necessários para suprir a descarga de sanitários e mictórios, a partir do uso de dispositivos como: limitadores de fluxo nos mictórios, e válvulas de descarga dupla com botão de alto e baixo fluxo. Já nas torneiras de pia e copas e chuveiros o projeto prevê cerca de 1.072.035 litros/ano de água potável.

Dados medidos do consumo real mostram que o uso de água proveniente da ETE destinado às descargas de sanitários e mictórios é aproximadamente 2.340 .000 litros/ano, e o consumo de água potável em torneiras e chuveiros se mostrou na média de 2.918 .000 litros por ano.

\subsection{Consumo de água pelo sistema de ar condicionado e espelho d'água}

Durante a entrevista com o coordenador de instalações do prédio em estudo, junto com a equipe terceirizada pela manutenção predial, e somando as informações obtidas pelo controle das contas de consumo de água, percebeu-se a existência de alguns fatores não considerados no sistema de certificação ambiental LEED, mas que influem fortemente no consumo mensal de água do prédio.

Conforme mostra o Quadro 4, o sistema de ar condicionado central por chillers já foi responsável por $61 \%$ do consumo de água especialmente nos meses quentes de verão, resultando $32 \%$ na média anual de consumo de água.

Outro fator que influencia na quantidade de água consumida é o espelho d'água construído no térreo do prédio. Este, já foi responsável por $55 \%$ do consumo total de água em um mês, em função de vazamento devido a problemas de má execução. Na média anual, o espelho d'água é responsável por 16\% no consumo de água.

O Quadro 4 mostra os dados de consumo de água, considerando o total, e as quantidades consumidas pelo ar condicionado e espelho d'água.

\section{Quadro 4 - Resumo dos consumos de água para Ar condicionado e Espelho d'água}

\begin{tabular}{|c|c|c|c|c|c|c|}
\hline Ano & Mês & $\begin{array}{c}\text { Total de } \\
\text { consumo de } \\
\text { água } \\
\text { (litros) }\end{array}$ & $\begin{array}{c}\text { Consumo de } \\
\text { água pelo Ar } \\
\text { Condicionado } \\
\text { (litros) }\end{array}$ & $\begin{array}{c}\text { Consumo de } \\
\text { água pelo } \\
\text { Espelho } \\
\text { d'água } \\
\text { (litros) }\end{array}$ & $\begin{array}{c}\text { Consumo de } \\
\text { água pelo Ar } \\
\text { Condicionado } \\
(\%)\end{array}$ & $\begin{array}{c}\text { Consumo de } \\
\text { água pelo } \\
\text { Espelho } \\
\text { d'água (\%) }\end{array}$ \\
\hline \multirow{2}{*}{2011} & Nov & 541.000 & 135.000 & 64.000 & 25 & 12 \\
\cline { 2 - 8 } & Dez & 645.000 & 176.000 & 68.000 & 28 & 11 \\
\hline \multirow{5}{*}{2012} & Jan & 678.000 & 225.000 & 51.000 & 34 & 8 \\
\cline { 2 - 8 } & Fev & 706.000 & 259.000 & 33.000 & 37 & 5 \\
\cline { 2 - 8 } & Mar & 786.000 & 297.000 & 153.000 & 38 & 20 \\
\cline { 2 - 8 } & Abr & 582.000 & 89.000 & 57.000 & 16 & 10 \\
\cline { 2 - 8 } & Mai & 188.000 & 62.000 & 15.000 & 33 & 8 \\
\cline { 2 - 8 } & Jun & 166.000 & 31.000 & 49.000 & 19 & 30 \\
\cline { 2 - 8 } & Jul & 300.000 & 10.000 & 164.000 & 4 & 55 \\
\cline { 2 - 7 } & Ago & 182.000 & 80.000 & 76.000 & 44 & 42 \\
\cline { 2 - 7 } & Set & 184.000 & 40.000 & 4.000 & 22 & 3 \\
\hline
\end{tabular}




\begin{tabular}{|c|c|c|c|c|c|c|}
\hline & Out & 340.000 & 111.000 & 131.000 & 33 & 39 \\
\hline & Nov & 656.000 & 234.000 & 62.000 & 36 & 10 \\
\hline & Dez & 461.000 & 279.000 & 50.000 & 60 & 11 \\
\hline \multirow{11}{*}{2013} & Jan & 588.000 & 272.000 & 100.000 & 47 & 17 \\
\hline & Fev & 686.000 & 264.000 & 48.000 & 39 & 7 \\
\hline & Mar & 456.000 & 196.000 & 35.000 & 43 & 8 \\
\hline & Abr & 391.000 & 145.000 & 45.000 & 38 & 12 \\
\hline & Mai & 319.000 & 51.000 & 36.000 & 16 & 12 \\
\hline & Jun & 201.000 & $5.000 *$ & $2.000 *$ & 3 & 1 \\
\hline & Jul & 369.000 & 68.000 & 75.000 & 19 & 21 \\
\hline & Ago & 150.000 & 24.000 & $4.000^{*}$ & 16 & 3 \\
\hline & Set & 192.000 & 61.000 & 10.000 & 32 & 6 \\
\hline & Out & 296.000 & 169.000 & 121.000 & 58 & 41 \\
\hline & Nov & 514.000 & 312.000 & 44.000 & 61 & 9 \\
\hline
\end{tabular}

Fonte: dados cedidos pela empresa (2014)

\subsection{Análise dos resultados obtidos}

O Quadro 5 sintetiza os resultados obtidos sobre o consumo de água no período analisado, comparando o consumo determinado pelo LEED, o consumo previsto no projeto e o consumo realizado.

\begin{tabular}{|c|l|l|l|l|c|}
\hline $\begin{array}{l}\text { Quadro 5 - Resumo } \\
\text { dos consumos para os } \\
\text { Requisitos }\end{array}$ & $\begin{array}{l}\text { Parâmetro } \\
\text { LEED } \\
\text { (l/ano) }\end{array}$ & $\begin{array}{l}\text { Parâmetro } \\
\text { projeto } \\
\text { (l/ano) }\end{array}$ & $\begin{array}{l}\text { Consumo } \\
\text { medido } \\
\text { (l/ano) }\end{array}$ & $\begin{array}{l}\text { Consumo em } \\
\text { relação } \\
\text { LEED } \\
(\%)\end{array}$ & $\begin{array}{l}\text { Consumo } \\
\text { em relação } \\
\text { ao projeto } \\
(\%)\end{array}$ \\
\hline 1 e 2: Paisagismo & 521.925 & 128.569 & 395.417 & $\mathbf{- 2 4}$ & $\mathbf{+ 2 0 7}$ \\
\hline 3: Água residual & 5.206 .301 & 1.253 .088 & 3.414 .530 & $\mathbf{- 3 4}$ & $\mathbf{+ 1 7 3}$ \\
\hline 4 e 5: Água de reuso & 1.641 .596 & 1.131 .831 & 2.340 .000 & $\mathbf{+ 4 3}$ & $\mathbf{+ 1 0 7}$ \\
\hline 4 e 5: Água potável & 1.488 .939 & 1.072 .035 & 2.918 .000 & $\mathbf{+ 9 6}$ & $\mathbf{+ 1 7 2}$ \\
\hline Total & 8.858 .761 & 3.585 .523 & 9.067 .947 & $\mathbf{+ 2 , 4}$ & $\mathbf{+ 1 5 3}$ \\
\hline
\end{tabular}

Fonte: Autora (2014)

No geral, nenhuma previsão de projeto foi atingida, e o consumo real medido se apresentou superior. Porém, observa-se que nos três primeiros requisitos, embora o consumo tenha se mostrado superior ao previsto no projeto, ainda é menor do que o previsto pelo programa LEED, porém, não atinge redução mínima de $50 \%$ no consumo de água, que, com base na quantidade prevista no projeto, creditou um ponto na certificação.

Quanto aos requisitos 4 e 5 o consumo medido de água se mostrou superior aos parâmetros estabelecidos pelo LEED e, consequentemente, bem acima dos parâmetros previstos no projeto.

Nos requisitos 1 e 2 , o projeto previu redução de água na irrigação de $76 \%$ do cálculo de referência do LEED. Na prática, o consumo de água de reuso na irrigação se mostrou apenas $24 \%$ inferior ao cálculo de referência do LEED. No requisito 3, o projeto previu que a ETE poderia reduzir sua capacidade de tratar água para $78 \%$ em relação ao cálculo 
de referência do LEED. Na prática, a ETE trata $35 \%$ a menos na capacidade prevista pelo cálculo de referência do LEED. Esta diferença de valores pode ser justificada com o aumento de consumo analisado nos próximos requisitos 4 e 5 referentes a água de reuso.

Nos requisitos 4 e 5 , o consumo da água de reuso se mostrou $43 \%$ superior ao cálculo de referência do LEED. Já na água potável, o consumo se mostrou $96 \%$ superior ao cálculo. Em ambos os casos, 2 pontos da certificação seriam perdidos por não terem atingido os mínimos de $20 \%$ e $30 \%$ de redução.

A partir da análise dos dados obtidos, buscou-se mais informações sobre a causa dos consumos de água de reuso e potável terem apresentado valor mais elevado que o projeto e o LEED com o coordenador de instalações do prédio. Segundo as informações obtidas, algumas possíveis justificativas para aumento da água de reuso nas bacias sanitárias e mictórios podem ser devido à maior frequência de limpeza destes reservatórios específicos já que a água de reuso após tratada ainda carrega uma dada quantidade de sólidos, e também uma considerável quantidade de entupimentos ocasionada pelo excesso de uso de papel higiênico hidrossolúvel que é descartada na rede de esgoto, que embora seja adaptada para receber este volume, faz com que as pessoas acionem mais descargas que o normal.

Já quanto ao aumento de água potável, foi explicado que a ETE (por ser uma tecnologia inovadora) demorou muitos anos para se adequar ao melhor tratamento químico. Enquanto estavam se adaptando à manutenção do mesmo, a ETE foi muitas vezes abastecida com água potável para não interromper o funcionamento do sistema em geral. Com o passar do tempo, esse abastecimento não será mais necessário.

O sistema de ar condicionado e o espelho d'água são decisões de projeto que merecem atenção devido à sua relevância no consumo de água. $\mathrm{O}$ uso de ar condicionado é primordial em um prédio comercial, e deverá ser melhor considerada outras opções que não utilizem água fria, porém essa decisão é complexa, porque também envolve questões de consumo de energia. Em alguns casos, quando se privilegia um dos fatores, o outro é prejudicado. Já o espelho d'água, outro elemento não contabilizado nos requisitos referentes ao consumo de água, poderia utilizar água da chuva ou um sistema de reservatório que utilizasse o mesmo volume de água apenas sofrendo um tratamento de limpeza, evitando que o volume total seja desperdiçado toda vez que uma troca total de água for necessária. Esses elementos mostraram grande influência no consumo de água do prédio, e não foram percebidos pela certificação, que é realizada na etapa de projeto.

\section{CONSIDERAÇÕES FINAIS}

Embora o projeto do prédio estudado tenha considerado um conjunto de estratégias para a redução no consumo de água potável, os resultados mostram que, no geral, os parâmetros estabelecidos pelo programa de certificação e previstos no projeto não foram atingidos, em grande parte, pelo fato de não serem consideradas duas fontes de consumo de água que impactam a quantidade consumida. Assim, observa-se uma fragilidade da pontuação na fase de projeto baseada em previsões, sem avaliação do consumo na fase de uso.

\section{AGRADECIMENTOS}

À CAPES/PROSUP (Coordenação de Aperfeiçoamento de Pessoal de Nível Superior), à UNISINOS (Universidade do Vale do Rio dos Sinos), à FAPERGS (Fundação de Amparo à Pesquisa do Rio Grande do Sul) e à UNISINOS pelo financiamento da pesquisa, através 
da concessão de bolsa e mestrado e iniciação científica, e à empresa participante, pela disponibilidade de documentos e entrevistas.

\section{REFERENCIAS}

BENINI, Humberto; CARMONA, Thomas; QUARCIONI, Valdecir; et al. Análise Simplificada de Sustentabilidade Pós-Ocupação de um Edifício Comercial. 2003.

GONÇALVES, Joana Carla Soares; DUARTE, Denise Helena Silva. Arquitetura sustentável: uma integração entre ambiente, projeto e tecnologia em experiências de pesquisa, prática e ensino. Ambiente construído, v. 6, n. 4, p. 51-81, 2006.

JOHN, Vanderley M. Reciclagem de Resíduos na Construção Civil: Contribuição à metodologia de pesquisa e desenvolvimento. Escola Politécnica da Universidade de São Paulo, 2000. Disponível em: <http://rmdaveiga.files.wordpress.com/2011/01/tesejohn.pdf>. Acesso em: 29 out. 2013.

JOHN, Vanderley M.; OLIVEIRA, Daniel Pinho; AGOPYAN, Vahan. Critérios de sustentabilidade para a seleção de materiais e componentes - uma perspectiva de países em desenvolvimento. 2006.

MACOZONMA, Dennis S. Construction Site Waste Management And Minimisation. África do Sul: International Council for Research and Innovation in Building and Construction (CIB), 2002. Disponível em: $<$ http://cibworld.xs4all.nl/dl/publications/Pub278/06Construction.pdf $>$. Acesso em: 6 jun. 2014.

PACHECO TORGAL, Fernando; JALALI, Said. A Sustentabilidade Dos Materiais de Construção. 1. ed. Minho: TECMINHO, 2010. Disponível em: $<$ http://www.livrariasaraiva.com.br/produto/3461614/a-sustentabilidade-dos-materiaisde-construcao $>$. Acesso em: 10 dez. 2013.

SILVA, Vanessa Gomes da; SILVA, Maristela Gomes da; AGOPYAN, Vahan. Avaliação de edifícios no Brasil: da avaliação ambiental para avaliação de sustentabilidade. Ambiente Construído, v. 3, n. 3, p. 7-18, 2003. (Ambiente Construído).

STUERMER, Monica Machado; BEDENDO, Ivana Aparecida; FELIPETTE, Pérola. A Certificação Verde LEED: reflexão de sua aplicação frente à Agenda 21Global. A Certificação Verde LEED: reflexão de sua aplicação frente à Agenda 21Global, p. 10, 2010. (Congresso Internacional Sustentabilidade e Habitação de Interesse Social).

Green Building Council Brasil. Green Building Council Brasil Site Oficial. Disponível em: <www.gbcbrasil.org.br>. Acesso em: 15 ago. 2014. 